\title{
BETTER SAFE THAN SORRY: SITUATIONAL CORRECTION IN INTERPERSONAL COMPETITION
}

\author{
Yan-mei Li \\ Chinese Academy of Sciences, China
}

Koji Murata

Hitotsubashi University, Japan

Shu Li

Chinese Academy of Sciences, China

\begin{abstract}
We conducted two experiments to investigate whether situational correction occurs when interpersonal competitors make dispositional inferences from their opponent's situationally constrained behavior. In both experiments, participants who expected interpersonal competition, judged a target person's disposition after reading information about a constrained or not constrained behavior of their opponent or non-opponent. As predicted, we found that insufficient situational correction occurred when the situationally constrained behavior of the opponent reflected a disposition that implied a high threat level (competitiveness or high ability) but sufficient correction occurred when the behavior reflected a low threat-level disposition (cooperativeness or low ability). Finally, we discussed the relationship between risk-avoidance and situational correction in competition.
\end{abstract}

If you know yourself and your enemy, you'll never lose a battle. -Chinese strategist Sun Tzu (6th century B.C.), The Art of War

The reported research was partially supported by National Natural Science Foundation of China (No. 70971127) and the Knowledge Innovation Project of the Chinese Academy of Sciences (No. KSCX2-YW-R-130).

We thank Prof. Ying-Yi Hong for her indispensable counsel and helpful comments on earlier versions of this article. We also thank He Tian for her contribution to this research and thank Drs. Edmund F. and Rhoda E. Perozzi for extensive English and content editing assistance.

Correspondence concerning this article should be addressed to Yan-mei Li, Institute of Psychology, Chinese Academy of Sciences, 4A Datun Road, Chaoyang District, Beijing, China, 100101. E-mail: liym@psych.ac.cn. 
In competition, people may benefit from knowing their opponent well because they can appraise their opponent's strengths, weaknesses, and strategies (Ruscher \& Fiske, 1990). How and how well do people know their opponent? In this study we investigated people's tendencies to judge their opponent's disposition in a situation in which they were expecting an interpersonal competition.

To gain understanding about others, people often observe the other person's behavior and infer his or her disposition from their behavior. Although behaviors are often determined or partially determined by situational factors, many studies have showed that people have a tendency to draw dispositional inferences even when another's behavior is situationally determined or constrained (e.g., Gilbert \& Jones, 1986; Jones \& Harris, 1967). This tendency toward insufficient situational discounting has been variously described as "fundamental attribution error" (Ross, 1977), "correspondence bias" (Gilbert \& Malone, 1995; Jones, 1979, 1990), or "dispositional bias" (Trope, 1998; Bierbrauer, 1979). Throughout this article, we will use the term dispositional bias. Will people make a situational correction if they infer their opponent's disposition when expecting an interpersonal competition? Our research investigates whether and how people adjust their dispositional judgment when making an inference from their opponent's situationally constrained behavior.

In Gilbert, Pelham, and Krull's (1988) dual-process model, three stages-behavioral categorization, dispositional characterization, and situational correction-follow each other sequentially to complete the process of dispositional inference. The first two of these stages are relatively automatic processes that need little effort or conscious attention, but situational correction is a deliberate and relatively controlled process that requires the perceiver's effort and cognitive resources (Gawronski, 2003; also see Bargh, 1994). Dispositional bias occurs when the perceiver is unable (e.g., does not have enough cognitive resources) or unwilling to make a situational correction about the dispositional inferences that he/she draws relatively automatically.

Some studies suggest that interdependence can lead people to allocate more cognitive resources and make more effort to understand a person on whom their outcomes depend and to improve the accuracy of their judgment, at least under some conditions (Neuberg \& Fiske, 1987).

It was found that people in interdependent (task dependent) situations pay increased attention to each other's attributes and to expectancy-inconsistent information (Erber \& Fiske, 1984; Neuberg \& Fiske, 1987; Ruscher \& Fiske, 1990; Stevens \& Fiske, 2000). When interdependence is symmetrical, people individuate others on whom their outcomes depend in both cooperative and competitive situations (Neuberg \& Fiske, 1987; Ruscher \& Fiske, 1990). When the dependence is asymmetrical, people whose outcomes depend more on others (e.g., powerless) individuate the others (e.g., power-holder) and do not discount information which is inconsistent with expectancy (Stevens \& Fiske, 2000). Because of its role in undercutting expectancy-based impressions and reducing stereotypic thoughts and evaluations, interdependence may somewhat improve the accuracy of judgments. 
However, studies which did not involve expectancy have suggested that insufficient situational correction may still occur in the inferences of interdependent individuals.

People in interdependent situations, such as dating or the prisoner's dilem$\mathrm{ma}(\mathrm{PD})$ game, have been found to make more extreme dispositional inferences (Berscheid, Graziano, Monson, \& Dermer, 1976; Miller, Norman, \& Wright, 1978 ) because they want to make future outcomes predictable and controllable by knowing the dispositions of the others (Heider, 1944, 1958) on whom their outcomes depend. Recent studies have also found that, although basic negotiation behavior is highly determined by bargaining positions, negotiators primarily interpret their counterpart's behavior in terms of the counterpart's personality, such as his or her level of cooperativeness or agreeableness (Morris, Larrick, \& Su, 1999). These findings imply that people in interdependent situations may not make sufficient situational corrections when making dispositional inferences based on their opponent's situationally constrained behavior because interdependence increases their desire to know their opponent's disposition. However, the above studies did not directly manipulate situational constraints.

\section{COMPETITION AND SITUATIONAL CORRECTION}

Interpersonal competition can be considered to be a type of interdependence (e.g., Ruscher \& Fiske, 1990; Vonk, 1998). However, interpersonal competition distinguishes itself from other types of interdependence in several ways. In interpersonal competition the interdependent outcomes of competitors are negatively correlated, such that the success of one individual necessitates the failure of the other (Deutsch, 1960, 1973; Ruscher \& Fiske, 1990). When a situation is structured competitively, individuals seek an outcome that is personally beneficial but detrimental to all others in the situation (Deutsch, 1962; Johnson \& Johnson, 1989). Nevertheless, each individual's goal may be thwarted by the capabilities of the other. These features of interpersonal competition are apt to become potential causes of insufficient situational correction.

The thwarted goals of competitors evoke hostility toward their opponent (Deutsch, 1960, 1973), but such hostility can lead perceivers to derogate their opponents' dispositions (Czopp, Monteith, \& Mark, 2006; Ross \& Ward, 1995). Klein and Kunda (1992) found that participants who expected competition rated their opponent's ability more negatively. Similarly, Sabatier, Hunter, and McLaughlin (1987) found that people impugn the motives and reasonableness of their opponents. However, these studies also did not directly manipulate situational constraints. In addition, the competitions in these studies were not interpersonal. Nevertheless, it is quite conceivable that interpersonal competitors may derogate their opponent to enhance themselves. If so, insufficient situational correction may be more likely to appear when their opponent's situationally constrained behavior appears to indicate a negative disposition. 
Vonk's study (1999) provided direct evidence to support this prediction. She found that people in a PD game took longer to process information about the other player when the other player's behavior was situationally constrained. She also found that the situational correction was significant when the other player's situationally constrained behavior was cooperative but that the situational correction was not significant when the other player's situationally constrained behavior was competitive. She argued that the reason that dispositional bias reduction (sufficient situational correction) did not appear when the behavior was individualistic was probably that the potential costs of an inaccurate judgment were higher in inferences relevant to socially negative dispositions (i.e., individualistic, dishonest), which are potentially damaging (Vonk, 1999).

However, for competitors the potentially damaging dispositions are not only such socially negative ones, but also any high-level abilities that are relevant to the competition task. Will people make a situational correction for a behavior of their opponent that reflects high ability?

\section{COMPETITORS' ESTIMATION OF THEIR OPPONENT'S ABILITIES: "BETTER SAFE THAN SORRY"?}

Findings by Chan and Ybarra (2002) showed that participants who expected interpersonal competition believed that it was more costly to underestimate than to overestimate how able one's opponent is and that their chances of success would be higher if they overestimated their opponents. Bond's study (1979) implies that this belief may influence people's judgment about their opponent's ability. He found that a future opponent was judged to possess higher levels of competition-relevant skills (i.e., quickness, intelligence) than a non-opponent. Vonk's research (1998) suggests that competition produces caution, careful processing, and conservative judgment as evidenced by the observation that participants in a competitive outcome-dependent situation did not derogate the task-relevant social skills of their opponent. They took more time to read the relevant information, and their judgments were moderate and relatively unaffected by initial expectancies (Vonk, 1998). The above findings imply that people who expect interpersonal competition may not derogate their opponent's task-relevant abilities; rather they may overestimate these abilities in an illustration of the phrase, "better to be safe than sorry." So it is possible that sufficient situational correction may not occur in an inference about an opponent's situationally constrained behavior which reflects high ability. Since situational correction will lower the estimation of these abilities and increase the risk of underestimating one's opponent; inferences like this are contrary to a competitors' usual caution and conservativeness.

\section{THE PRESENT RESEARCH}

To summarize, few studies exist about how people who expect interpersonal competition infer their opponent's dispositions from his/her situationally con- 
strained behaviors and whether they make a situational correction, although we can find everyday indications of this in the real world. Even fewer studies have investigated situational correction from the perspective of perceived threat. We conducted the following studies to explore these issues.

We reasoned that cautiousness may influence whether a situational correction will be sufficient. When an opponent's behavior reflects a disposition that implies a high threat level (i.e., competitiveness or high ability), a sufficient situational correction will lower the threat level of the disposition and may increase the risk of underestimating the opponent. The potential cost will be high if the inference is wrong. However, insufficient situational correction will maintain a high threat level and may keep competitors alert. In this case the potential cost will be low if the inference is wrong. However, when an opponent's behavior reflects a low threat-level disposition (i.e., cooperativeness or low ability), a sufficient situational correction will increase the threat level and may lower the risk of underestimating the opponent. Thus the potential cost will be low if the inference is wrong. Insufficient situational correction, on the contrary, will keep the threat level low, so the potential cost will be high if the inference is wrong. Therefore, we predicted that insufficient situational correction is more likely to occur when an opponent's situationally constrained behavior reflects a disposition that implies a high threat level than when the behavior reflects a low threat-level disposition. We conducted two experiments to test this prediction.

In competition, people may be quite concerned about their opponent's cooperativeness and their task-relevant ability because cooperativeness determines their choice of strategy and ability determines task performance. In Experiment 1, we focused on cooperativeness, and predicted that situational correction is more likely to occur when an opponent's situationally constrained behavior is cooperative (reflects low threat-level disposition) than that when the behavior is competitive (reflects high threat-level disposition; Hypothesis 1). However, this predicted result could be interpreted as an effect of negativity bias (Skowronski \& Carlston, 1989; Taylor, 1991) because competitive or cooperative behaviors can be considered to be behaviors with negative or positive valences. Alternatively, this predicted result could be interpreted as an effect of a desire to derogate an opponent (Klein \& Kunda, 1992; Sabatier et al., 1987) because a sufficient situational correction about cooperative behavior will decrease the positive evaluation (i.e., cooperative) about an opponent and an insufficient situational correction about competitive behavior will maintain the negative evaluation (i.e., competitive) about an opponent. To rule out these alternative explanations, we focused on ability in Experiment 2, and predicted that situational correction is more likely to occur when an opponent's situationally constrained behavior reflects low ability (low threat-level disposition) than when the behavior reflects high ability (high threat-level disposition; Hypothesis 2). 


\section{PILOT STUDY}

Before performing the main experiments, we investigated whether an opponent's competitiveness and task-relevant ability are dispositions with which people are particularly concerned when expecting an interpersonal competition. We asked 16 students (7 male, 9 female) from four Japanese universities to answer the following five questions, "To what extent are you concerned about your opponent's task-relevant ability when you are expecting to compete with him/her?" and "To what extent are you concerned about whether your opponent is an intelligent (or a competitive, trustworthy, friendly) person when you are expecting to compete with him/her?" on a 1 (not at all) to 7 (very) scale.

The results showed that participants were concerned with their opponent's task-relevant ability and competitiveness $(M=6.38, S D=0.50 ; M=6.06, S D$ $=0.77$ ) more than with their opponent's intelligence, trustworthiness, and friendliness $(M=5.63, S D=0.72 ; M=4.13, S D=1.20 ; M=3.69, S D=1.08$, respectively) when they were expecting an interpersonal competition (all $p s<$ .05 for pairwise comparisons contrasting ability or competitiveness with the other three items, except for the intelligence/competitiveness comparison for which $t[15]=1.96, n s)$. This focus for their concern on ability and competitiveness may occur because understanding an opponent's task-relevant ability and competitiveness seems to participants to be more helpful for them in controlling and predicting their outcomes than the other's dispositions. In addition, we found that participants' evaluations about ability and intelligence $(r=.60$, $p<.01)$, ability and competitiveness $(r=.45, p<.08)$, and trustworthiness and friendliness $(r=.55, p<.03)$ were positively related; whereas competitiveness and trustworthiness $(r=-.51, p<.04)$ and competitiveness and friendliness $(r=$ $-.62, p<.01)$ were negatively related. Other correlations were not significant.

\section{EXPERIMENT 1}

\section{OVERVIEW}

We conducted Experiments 1a and $1 \mathrm{~b}$ to test whether situational correction is more likely to occur when an opponent's situationally constrained behavior is cooperative than when the behavior is competitive (Hypothesis 1).

In Experiment 1a, we used a questionnaire to explore the perceived threat level of an opponent's disposition (cooperative or competitive) when people are expecting to compete with him/her.

In Experiment 1b, participants were led to believe that they would compete with another participant in a game for a chance to win a prize. First, they practiced five game trials and then read information about the strategy that their future opponent or non-opponent had supposedly used in the practice trials. The strategy was supposedly either competitive or cooperative, and the specific strategy was either freely chosen by the person himself/herself or advised (recommended by game researchers). Finally they completed a questionnaire 
that asked them to judge the cooperativeness of their future opponent or nonopponent.

\section{EXPERIMENT $1 \mathrm{~A}$}

To investigate how much people feel that their opponent's disposition (cooperative or competitive) threatens their desired outcome (win) when they are expecting to compete with him/her, we conducted the following study:

Participants (13 female and 8 male students from Shoin University) were informed that the study was a short psychology questionnaire about interpersonal perception. They were given a questionnaire containing a competitionrelated scenario, which read:

Please imagine that you are going to play a two-person trade-off game ${ }^{1}$ with five trials. The rules of the game are as follows:

Each player has ten 10-yen coins as a fund for each trial. First, each player will decide individually how many coins they want to give to the other player and write the number into a "Trade-off Table." Then, the two players (you are one of them) will show the number to each other simultaneously, write the number of coins that you would get from each other into the "Income Table," and use the following formula to calculate each person's income.

Your income $=\{$ coins kept for yourself $+2 \times($ coins your opponent gave you $)\} \times 10$.

The income for both of you will be the same if you give the same amount of money to each other; you will have more income if you give less than what your opponent gave you and vice versa. The winner will be the one who has more income.

Participants then answered four questions, "Do you feel that the other player will threaten your desired outcome (win) if he/she is a competitive (or cooperative) person?" and "What do you think is the probability that you can win the game if the other player is a competitive (or cooperative) person?" on a 1 (not at all threatening/very low) to 7 (very threatening/very high) scale. After they completed the questionnaires, the participants were debriefed and thanked for their participation.

The results showed that the participants felt their outcome would be threatened more if the other player was a competitive $(M=5.71 ; S D=0.90$ rather than a cooperative $(M=2.95 ; S D=0.80)$ person, $t(20)=9.21, p<.001)$. The participants' perceived probability of winning was significantly lower when the other player was thought to be a competitive $(M=3.95 ; S D=1.02)$ than when the other player was thought to be a cooperative $(M=5.24 ; S D=1.04)$ person, $t(20)=-4.26, p<.01$. More importantly, we found that their perception of the threat level of an opponent's disposition was significantly correlated with a

1. The game was first used in Murata's (1982) experiment. 
perceived low probability of winning, $r_{\text {competitive }}(21)=-.67, p<.01 ; r_{\text {cooperative }}(21)=$ $-.76, p<.01$. Therefore, the higher the threat level of an opponent's disposition (i.e., competitiveness), the lower the perceived probability of a win. ${ }^{2}$

\section{EXPERIMENT 1B}

\section{Participants and Design}

The participants were 98 Japanese undergraduates ( 54 male, 44 female, mean age $=20.3)$ from Shoin University. They were distributed across the conditions of a 2 (opponent: opponent vs. non-opponent) $\times 2$ (advice: advice vs. nonadvice) $\times 2$ (strategy: competitive vs. cooperative) factorial design.

\section{Procedure}

On arrival, two apparent participants (one participant, one confederate) were seated in separate individual cubicles. An experimenter first told them that another two participants were participating in the experiment at the same time in the next room and then introduced the concept that the study is about the effect of competition and information on decisionmaking. In addition the experimenter told them that each of them will play a two-person competition game with one of the participants in the next room. Thus one of the supposed players in the other room would become their future opponent and the other would be called their "non-opponent." She further explained that two types (with or without advice about game strategy) of pamphlets about the experimental procedure had been prepared, and showed participants samples of each type. Participants selected their own pamphlet from 20 copies, which were described as including 10 copies of each type. In fact, all the participants' pamphlets were the "without advice" type.

Subsequently, the participants read the "Introduction to the Experiment" and "Introduction to the Game" sections (briefly as follows) in their pamphlet while listening to the experimenter's explanation.

Introduction to the Experiment: There are three steps in the experiment. First step (Practice): Practice five trials of the competition game with the participant in front of you. Second step (Information exchange): Draw lots to decide whether you will read your future opponent's or a non-opponent's information. Then read the information and complete a questionnaire about the information. Last step (Competition): Have ten trials of the game with your opponent. The winner will be awarded some chocolate as a prize.

2. Experiments $1 \mathrm{a}$ and $2 \mathrm{a}$ were conducted after Experiments $1 \mathrm{~b}$ and $2 \mathrm{~b}$. 
Introduction to the Game: (Please see the scenario from Experiment 1a. The only differences are that we used a "Practice Trade-off Table" and a "Practice Income Table" here instead of a "Trade-off Table" and an "Income Table.")

Before the practice trials, the experimenter asked participants whether they found any advice in their experiment paper and asked them to place the answer to the question "Is there any advice in your experiment paper?" by the question, which was under the "Practice Trade-off Table" in their pamphlet. If they found advice in their folder, the experimenter asked them to use the advice by entering the number of coins that the pamphlet recommended. If the pamphlet did not give them any advice, they should make their own choice about how much money to put down. Of course no advice appeared in any of their pamphlets. Then the participants practiced five trials with the confederate. To avoid influencing the outcome (gain or loss) during this practice, the number of coins that the confederate wrote down was " $5,4,6,4,5$ "; that is, the strategy was neither competitive nor cooperative.

The participants then drew lots twice, and the experimenter told them to write the result of their first draw on the upper right corner of their "Practice Trade-off Table." They were led to believe the following:

1. The first draw (either " $A$ " or " $B$ ") would determine their future opponent-the participant in the next room who drew the same letter as they.

2. The second draw ("opponent" or "non-opponent") determined whether the participants would get to read the supposed information for their future opponent or not. Those whose second draw was the "opponent" lot would read their future opponent's information, and the rest would read the non-opponent's information. The non-opponent refers to the participant in the next room whose first lot was different from theirs. The information they would receive would be a copy of the "Practice Tradeoff Table" that either their opponent or the non-opponent had filled out during their practice session.

3. The participants in the next room would also receive copies of the "Practice Trade-off Table" of the participants in this room as their source of information using the same procedure as above.

To summarize, participants who drew A/"opponent" would expect to play person A from the supposed game in the next room and would get to see the results of their practice rounds as indicated in their "Practice Trade-off Table." The same would be true for people who drew B/"opponent," only with person B. But the students who drew A/"non-opponent" or B/"non-opponent" would play the first person, but only see the results of the person whom they would not play. Of course, none of these perceptions were true, as we manipulated the outcomes in the following ways. 
Subsequently, the experimenter gave the participants a copy of the "Rules of the Final Games" to read, and left the room after explaining that she was going to make copies of their pamphlets for the use of their opponents in the other room. After coming back to the room, she returned the pamphlets, and gave the participants forged information copies that appeared to be marked according to their lot-drawing.

Each information copy included a "Practice Trade-off," an answer to the question whether that person had received any advice, and a handwritten " $A$ " or "B." Of course we had previously prepared eight types of information copies to manipulate the three independent variables:

Strategy Variable. The participants who received a copy in which the coin numbers in the "Practice Trade-off Table" that their opponent had supposedly prepared were " $1,2,2,1,0$ " formed the competitive strategy condition. The participants who received a copy in which the numbers were " $7,6,8,9,7$ " formed the cooperative strategy condition.

Opponent Variable. The participants who received a copy with a handwritten " $\mathrm{A}$ " or " $\mathrm{B}$ " that was the same as the letter they had received in their first draw, became the opponent condition. The participants who received a copy with a letter different from their own became the non-opponent condition.

Advice Variable. The participants who received a copy in which the answer to the question "Have you received any advice about the game strategy?" was "Yes," indicating that their presumed target (either opponent or non-opponent, depending on the results of the second drawing) had received advice, formed the advice condition. The participants who received a copy in which the answer was "No," formed the non-advice condition. This variable constituted situational constraint in the perception of the participants.

Participants then read the information and completed the "Information Questionnaire," which included a manipulation check, dependent measures, and some other questions. As a manipulation check, we asked "Whose information did you read? Your opponent's or a non-opponent's?" and "Did that person received any advice?" We also asked participants to evaluate "the probability that you can win if you are competing with that person" on an 11-point scale ranging from 1 (very low) to 11 (very high) to check whether dispositional inference could be used to predict a person's outcome. As an easily answered dependent measure, the cooperative condition participants were asked "To what extent do you think that the other person is a cooperative person?" and the competitive condition participants were asked "To what extent do you think that the other person is a competitive person?" on an 11-point scale ranging from 1 (definitely is not) to 11 (definitely is). ${ }^{3}$ After the participants completed the questionnaire, the experimenter announced that the experiment was finished, and gave the participants a detailed debriefing.

3. To test the similarity of these two scales, we asked 18 students of Shoin University to rate "When a very cooperative person and a very uncompetitive person face a choice about whether they will cooperate or compete, how similar will they be in their choices?" on an 11-point scale ranging from 1 (completely different) to 11 (completely the same). The result showed that they believed a very uncompetitive person was very similar to a very cooperative person while facing a choice between cooperation and competition $(M=8.89, S D=1.78)$. 
TABLE 1. Means and Standard Deviations of Cooperative Judgments (1-11) as a Function of Opponent, Advice, and Strategy

\begin{tabular}{lll}
\hline & \multicolumn{3}{c}{ Behavior } \\
\cline { 2 - 3 } & Competitive & Cooperative \\
\hline $\begin{array}{l}\text { Non-opponent } \\
\text { Non-advice }\end{array}$ & $4.18_{\mathrm{a}}(1.40)$ & $7.64_{\mathrm{a}}(1.50)$ \\
Advice & $4.46_{\mathrm{a}}(1.66)$ & $7.82_{\mathrm{a}}(1.72)$ \\
Opponent & & $8.17_{\mathrm{a}}(1.64)$ \\
Non-advice & $4.31_{\mathrm{a}}(1.38)$ & $6.27_{\mathrm{b}}(1.62)$ \\
\hline
\end{tabular}

Note. Cell means within one row with different subscripts differ at the .05 level.

Participants were thanked by being given the chocolate that had been promised as a prize for the winner.

We predicted that when the strategy was cooperative, participants of the opponent-advice condition would be more likely to rate the cooperativeness of the person in the information lower than participants in the opponent-nonadvice condition, than participants in the non-opponent-advice condition or than participants in the non-opponent-non-advice condition (Hypothesis 1a). We also predicted that the above differences would be difficult to observe when the strategy was competitive (Hypothesis $1 b$ ).

\section{RESULTS AND DISCUSSION}

Three participants in the non-opponent condition misunderstood and thought that their information was about their future opponent. An additional three participants in the advice condition thought that their perceived target had not received any advice. We excluded their data from our analysis.

\section{Test of Hypothesis}

First, the scores of the competitive condition participants were reversed to yield a cooperativeness indicator based on the finding of the close relationship between cooperation and uncompetitiveness (see footnote 3 ). Then, the participants' ratings of the cooperativeness of the perceived target were examined in a opponent $x$ advice $x$ strategy analysis of variance, which produced a marginal three-way interaction, $F(1,84)=3.50, p=.06, \eta^{2}=.04$. Table 1 shows the cell means and the results of a simple main effect. As predicted, when the strategy was cooperative, the cooperativeness of an opponent whom the participant thought had received advice was rated significantly lower than that of an opponent who was thought to have not received advice, $t(21)=2.87, p<.01$ or of a non-opponent who was presumed to have received advice, $t(20)=2.25$, $p<.05$, or who did not receive advice, $t(20)=1.99, p<.05$. In contrast, when the strategy was competitive, the cooperativeness of an opponent whom the participant thought had received advice was rated not significantly different from 
that of an opponent who did not receive advice or from that of a non-opponent who was perceived as having received advice or who did not receive advice, $t(21)=1.02, n s, t(21)<1, n s, t(19)=1.17$, ns, respectively.

These results indicate that participants whose opponent's cooperative behavior was perceived as having been situationally constrained made a sufficient situational correction in their dispositional inference because their rating of their opponent's cooperativeness was significantly lower than that of the other three cooperative conditions. These results also indicate that participants whose opponent's competitive behavior was situationally constrained did not make a sufficient situational correction because their rating of their opponent's cooperativeness was not significantly different from the other three competitive conditions. These findings, along with the findings of Experiment 1a, support our Hypothesis 1 that situational correction is more likely to occur when an opponent's situationally constrained behavior is cooperative (reflects low threat level disposition) than that when the behavior is competitive (reflects high threat level disposition).

Additionally, the analysis revealed a main effect of strategy. Cooperative condition participants $(M=8.13, S D=1.78)$ rated their target as significantly more cooperative than did the competitive condition participants $(M=4.47, S D=$ $1.52), F(1,84)=116.37, p<.001, \eta^{2}=.58$. The analysis also revealed a behavior $\times$ advice interaction, $F(1,84)=4.07, p<.05, \eta^{2}=.05$. When the strategy was cooperative, the cooperativeness of a perceived target who received advice was rated marginally lower than that of a target who did not receive advice, $t(43)$ $=1.82, p<.08$, and $M=7.68, S D=1.86 ; M=8.57, S D=1.62$, respectively. There was no significant difference when the strategy was competitive, $t(45)=1.03$, $n s$, and $M=4.70, S D=1.66 ; M=4.25, S D=1.36$, respectively.

\section{Perceived Win Probability}

The participants' perceived probability of defeating their perceived target was examined in an opponent $x$ advice $\times$ strategy ANOVA, which produced a main effect of strategy, $F(1,84)=29.31, p<.001, \eta^{2}=.26$. Participants whose perceived target's (either their expected opponent's or the non-opponent's) behavior reflected a cooperative strategy rated their probability of winning as higher than participants whose target's behavior reflected a competitive strategy $(M=7.31, S D=2.11 ; M=5.15, S D=1.76$, respectively). The analysis also produced a main effect of opponent, $F(1,84)=4.51, p<.04, \eta^{2}=.05$. Participants who were assigned to read information about non-opponents rated their probability of winning as higher than participants who read about their opponent $(M=6.59, S D=2.04 ; M=5.83, S D=2.33$, respectively).

These results indicated that competitiveness was perceived to be quite threatening to the desired outcome (win) because, compared with participants whose perceived target behaved cooperatively, participants whose target behaved competitively rated their probability of winning as much lower. The results of the probability of a winning analysis also indicated that people may make cautious and conservative judgments regarding their future opponent, 
as Vonk (1998) suggested, because participants thought they had less chance to win against a competitor that they thought would be their opponent than against one that they knew would not be their opponent, that is, a non-opponent.

However, as we mentioned in the introduction, the results of Experiment $1 \mathrm{~b}$ could be interpreted as an effect of negativity bias because competitive or cooperative behaviors can be considered as behaviors with negative or positive valences. These results could also be interpreted as an effect of a desire to derogate an opponent because a sufficient situational correction about cooperative behavior will decrease a positive evaluation (cooperative) of an opponent, and an insufficient situational correction about competitive behavior will maintain a negative evaluation (competitive) about an opponent. To rule out these alternative explanations, we manipulated ability in Experiment 2. Low or high ability behavior can also be interpreted as behaviors with negative or positive valences. Because our prediction is that situational correction is more likely to occur when an opponent's situationally constrained behavior reflects low ability (low threat-level disposition) than when the behavior reflects high ability (high threat-level disposition), this tendency could not be interpreted as effects of negativity bias or the desire to derogate an opponent. Specifically, either a sufficient situational correction about low-ability behavior-a negative behavior-or an insufficient situational correction about high-ability behavior-a positive behavior-will increase or maintain the positive evaluation of an opponent.

In Experiment 1b, we took into consideration the participants' convenience in answering the questions so we used separate scales for the cooperative and competitive conditions. We found that people thought a definitely not competitive person was very similar to a definitely cooperative person when facing a choice between cooperation and competition (see footnote 3 ). Since in facing the choice between cooperation and competition a definitely not competitive person surely will not choose competition, his or her likelihood of cooperation is as high as a definitely cooperative person. Nevertheless, a low score on competitiveness does not necessarily mean a high score on cooperativeness. To remedy this limitation, in Experiment $2 b$, we used a single scale (math ability) to measure all the participants' dispositional inferences.

\section{EXPERIMENT 2}

\section{OVERVIEW}

We conducted Experiments $2 \mathrm{a}$ and $2 \mathrm{~b}$ to test whether situational correction is more likely to occur when an opponent's situationally constrained behavior reflects low ability than when the behavior reflects high ability (Hypothesis 2).

In Experiment 2a, we used a questionnaire to explore the perceived threat level of an opponent's disposition (high ability or low ability) when people are expecting to compete with him/her. 
In Experiment 2b, participants were led to believe that later they would compete against another participant in a math task for a chance to win a prize. Participants first completed a warm-up math task and then read information which pretended to reveal their future opponent's or non-opponent's performance in the warm-up task. The performance supposedly reflected either high or low math ability, and the task was supposedly either freely chosen by the person himself/herself or was assigned by the researcher. Finally participants completed a questionnaire to judge the math ability of their future opponent or non-opponent.

\section{EXPERIMENT 2A}

We conducted a study to investigate how threatening math ability is when people expect a competition which is related to math. Participants (15 male and 8 female, students from Wasada University) were informed that the study was a short psychology questionnaire about interpersonal perception. They were given a questionnaire containing a competition-related scenario. The scenario read:

You are going to play a two-person game which is related to math. Two players separately select a math question for each other from a question list and answer the question selected by the other player in 1.5 minutes. After five repeats of this process, your answers will be checked, and the one who has more correct answers will be awarded a prize.

Participants then answered four questions, "Do you feel the other player would threaten your desired outcome (win) if he/she is a person who is (or is not) good at math?" and "What do you think is the probability that you can win the game if the other player is (or is not) good at math?" on a 1 (not at all threatening/very low) to 7 (very threatening/very high) scale. After they completed the questionnaires, the participants were debriefed and thanked for their participation.

The results showed that the participants felt that their outcome would be threatened more if the other player was good at math $(M=5.88 ; S D=1.15)$ than if he/she was not good at math $(M=3.17 ; S D=1.09, t(23)=7.25, p<.001$. The participants' perceived probability of winning was significantly lower when the other player was good at math $(M=3.75 ; S D=1.11)$ than when the other player was not good at math $(M=5.21 ; S D=1.18, t(23)=-3.93, p<.001$. More importantly, we found that a threat level based on an opponent's math ability was significantly correlated with a perceived probability of a win, $r_{\text {high }}$ math ability $\left(24=-.74, p<.001 ; r_{\text {low math ability }}(24)=-.71, p<.001\right.$. Therefore, the higher the threat level of an opponent's math ability, the lower the perceived probability of a win. 


\section{EXPERIMENT 2B}

\section{Participants and Design}

The participants were 95 Japanese undergraduates (63 male, 32 female) from Waseda University. They were randomly assigned to one of the conditions of a 2 (opponent: opponent vs. non-opponent) $\times 2$ (choice: choice vs. assigned) $\times 2$ (performance: good vs. poor) factorial design.

\section{Experimental Materials}

We asked five students at Waseda University to evaluate the difficulty of 16 math questions (12 of these had been used in Li's, study, and 4 easy questions were added). According to their judgment, there were eight easy ones in the 16 questions, but that long descriptions made three of the easy questions look difficult.

\section{Procedure}

Four or six participants participated in the experiment together. On arrival, they were randomly seated in individual cubicles. A white card printed with an " $A$ " or " $B$ " was laid on the table of each cubicle.

After introducing herself and her assistant, the experimenter explained that psychology research had recently found that math tasks facilitate concentration and analytical thinking. The purpose of the study was to investigate whether this finding could be used in competition. Then the participants read the "Introduction to the Experiment" (briefly as follows) while listening to the experimenter's explanation.

"The experiment has three steps. In the first step (warm-up), you will answer seven math questions in 10 minutes. The answers will be checked and graded anonymously by the assistant. In the second step (information-exchange), lots will be drawn to decide if you will read your future opponent's or a non-opponent's information. Then you will read the information and complete a questionnaire about the information. In the last step (competition), you will compete with one of the other participants in a new math task. In each trial..... (Please see the scenario in Experiment 2a). Who will become your opponent will depend on the card on your table. Participants whose cards happen to have the same letter (seat number) will compete with each other."

The experimenter then explained that in the warm-up step there were two types of tasks-questions chosen by self (free-choice tasks) or assigned by the researcher (assigned tasks) from the same 16 questions-and there were several sets of assigned tasks of which some were very easy, even easier than the 
free-choice tasks, as well as some that were very difficult. She showed one sample of a free-choice task, as well as very quickly showing three samples of assigned tasks, so that participants had no time to evaluate the easiness of any question. Participants then chose their task paper from 20 copies, which were described as being subdivided into ten copies of free-choice tasks and ten copies of assigned tasks. In fact all papers were free-choice tasks. Participants then answered the questions. Ten minutes later they were asked to stop and open the evaluation page of their task paper which included four items, briefly as follows.

1. Please fill in your participant number (the number on the cover of your paper)

2. Please circle your seat number: A B C

3. Please circle the type of your task: (a) Assigned (b) Free-choice

4. Your task performance in the warm-up: on a 9-point scale (from A+, A, A-, B, B-... to E)

The participants finished the first three items themselves. For the performance evaluation, the experimenter explained: " $\mathrm{A}+$ ' means that a person correctly answered more than seven questions; ' $E$ ' means that a person's answers were all wrong. The assistant will check your answers, place the correct task performance for item 4 on your evaluation page, and copy your pages. The copies will be used as information either for your future opponent or non-opponent." The assistant collected the participants' papers and left the room.

Then participants were led to believe that some people had actually received an "assigned easy task" in the warm-up step in the following two ways.

1. They were told to read the "Pilot investigation of warm-up math tasks" (briefly as follows)

"Although the average scores of free-choice and assigned tasks were both " $B$," the average scores of assigned easy and difficult tasks were "A-" and " $C$," respectively. The better score on the assigned easy tasks was due to the fact that participants who were given the free-choice option did not have enough time to read the 16 questions thoroughly so that they could choose the really easy ones."

2. The experimenter showed the participants samples of the assigned easy and difficult tasks.

After drawing lots to decide whether they could read their future opponent's information, the participants read the "Competitive task introduction," which was used to lead participants to believe that they were going to compete against another participant in a new math task.

The assistant came back with forged information copies. Eight kinds of copies were prepared to manipulate three independent variables. 
Opponent Variable. If the participants received a copy in which the circled seat number was same as their own, they formed the opponent condition. The participants who received a copy in which the circled seat number was different from their own formed the non-opponent condition.

Choice Variable. If the participants received a copy in which "free-choice" was circled, they formed the choice condition. The participants who received a copy, in which "assigned" was circled became the assigned condition.

Performance Variable. If the participants received a copy in which their opponent or non-opponent's rating of "Task performance in warm-up" was "A," they formed the good performance condition. The participants who received a copy in which the rating was " $\mathrm{C}-$ " formed the poor performance condition.

After reading the information, the participants completed an "Information Questionnaire." In the questionnaire, as a dependent measure, we asked them to evaluate the "level of your target's math ability" on an 11-point scale ranging from 1 (very low) to 11 (very high). As a manipulation check, we asked "Whose information did you read? Your opponent's or non-opponent's?" "What was the type of that person's task? Assigned or free-choice?" and "If that person's task was assigned, please answer whether you think the task was difficult." We also asked participants to evaluate "the probability that you can win a math competition with this person" on an 11-point scale ranging from 1 (very low) to 11 (very high) to check whether dispositional inference can be used to predict an opponent's future behavior and a person's outcome in competition.

After the participants completed the questionnaire, the experimenter announced that the experiment was finished, and gave them a detailed debriefing. Participants were thanked by sharing the chocolate that they had previously been told would be a prize for the winner.

Here we expected that if the performance that the participants read for their opponent was poor, participants of the opponent-assigned condition would be more likely to rate the ability of the person in the information higher than participants in the opponent-free-choice condition, than participants in the non-opponent-assigned condition, or than participants in the non-opponentfree-choice condition (Hypothesis 2a). We also expected that the above differences would be difficult to observe when the performance was good (Hypothesis $2 b$ ).

\section{RESULTS AND DISCUSSION}

As expected, participants in the poor-performance-assigned condition thought the assigned task of their perceived target had been difficult, and most participants in the good-performance-assigned condition thought their target's assigned task had been easy. Three participants in the good-performance-assigned condition thought their target's assigned task had been difficult, and one additional participant correctly guessed that the last (competition) step 
TABLE 2. Means and Standard Deviations of Math Ability Judgments (1-11) as a Function of Opponent, Choice, and Performance

\begin{tabular}{lcc}
\hline & \multicolumn{2}{c}{ Performance } \\
\cline { 2 - 3 } & \multicolumn{1}{c}{ Good } & Poor \\
\hline Non-opponent & & \\
Choice & $8.54_{\mathrm{a}}(1.33)$ & $4.50_{\mathrm{a}}(1.45)$ \\
Assigned & $9.00_{\mathrm{a}}(1.49)$ & $4.91_{\mathrm{a}}(1.76)$ \\
Opponent & & \\
Choice & $9.33_{\mathrm{a}}(1.32)$ & $4.54_{\mathrm{a}}(1.51)$ \\
Assigned & $8.45_{\mathrm{a}}(1.57)$ & $6.25_{\mathrm{b}}(1.66)$ \\
\hline
\end{tabular}

Note. Cell means within one row with different subscripts differ at the .05 level.

did not actually exist in our experiment. We excluded these four participants' data from our analysis.

\section{Test of Hypothesis}

The participants' ratings of the math ability of their perceived targets were examined in a opponent $x$ choice $x$ performance analysis of variance, which produced a three-way interaction, $F(1,83)=4.25, p<.05, \eta^{2}=.05$. Table 2 shows cell means and the results of the simple main effect. As expected, when the performance was poor, the ability of an opponent whose task was assigned was rated significantly higher than that of an opponent whose task was freely chosen, $t(23)=2.82, p<.01$, and of that of a non-opponent whose task was assigned, $t(21)=2.12, p<.05$, or freely chosen, $t(21)=2.82, p<.01$. In contrast, when the performance was good, the ability of an opponent whose task was assigned was not rated as significantly different from that of an opponent whose task was freely chosen and a non-opponent whose task was assigned or freely chosen, $t(18)=1.29, n s, t(19)<1, n s$, and $t(22)<1, n s$, respectively.

These results indicated that participants whose opponent's poor performance was situationally constrained made a sufficient situational correction for their dispositional inference because their rating of their opponent's ability was significantly higher than for the other three poor-performance conditions. These results also indicated that participants whose opponent's good-performance was situationally constrained did not make a sufficient situational correction because their rating of the opponent's ability was not significantly different from the other three good performance conditions. Along with the findings of Experiment 2a, these findings are consistent with our Hypothesis 2 that situational correction is more likely to occur when an opponent's situationally constrained behavior reflects low ability (low threat-level disposition) than that when the performance reflects high ability (high threat-level disposition).

Additionally, the analysis revealed a main effect of performance. Good-performance condition participants rated the math ability of the supposed target significantly higher than did poor performance condition participants, $F(1$, 
$83)=139.16, p<.001, \eta^{2}=.63$, and $M=8.79, S D=1.46 ; M=5.04, S D=1.70$, respectively. The analysis also revealed a marginal interaction of behavior $x$ choice, $F(1,83)=3.92, p=.05, \eta^{2}=.05$. When performance was perceived to be poor, the math ability of a perceived target whose task was assigned was rated significantly higher than that of a target whose task was freely chosen, $t(46)=2.41, p<.02$, and $M=5.61, S D=1.52 ; M=4.52, S D=1.45$, respectively. There was no significant difference when the opponent's or non-opponent's performance was good, $t(41)<1, n s$, and $M=8.71, S D=1.52 ; M=8.82, S D=$ 1.44 , respectively.

\section{Perceived Win Probability}

The participants' perceived probability of winning against the perceived target was examined in a opponent $\times$ choice $\times$ performance analysis of variance, which produced a main effect of performance, $F(1,83)=11.94, p<.001, \eta^{2}=.13$. Participants whose target's performance was poor rated their probability of winning as being higher than that of participants whose target's performance was good, $M=6.67 ; 5.21$, respectively.

These results indicated that high ability was perceived as more threatening to the desired outcome (win) than low ability, because participants, whose target's performance seemed to reflect high ability, rated their probability of winning as much lower than participants whose target's performance seemed to reflect low ability.

\section{GENERAL DISCUSSION}

The results about dispositional inferences from both experiments suggest that insufficient situational correction is more likely to occur when an opponent's situationally constrained behavior reflects a disposition that is perceived as being of a high threat level (i.e., competitiveness or high ability), than when the behavior reflects a disposition that has a low threat level (i.e., cooperativeness or low ability). This tendency is consistent with our basic prediction and may be due to the effect of the cautiousness and conservativeness of competitors. Since an insufficient situational correction maintains the perception of an opponent's threat when his or her behavior reflects a high threat-level disposition and since a sufficient correction increases the perception of an opponent's threat when the behavior indicates a low threat-level disposition, either alternative could serve to make a competitor more fully aware of an opponent's threat and thus help the competitor to stay alert. Moreover, the potential cost will be low even if the inferences are wrong. That is, it is "better to be safe than sorry." 


\section{MOTIVATION AND COMPETITORS' SITUATIONAL CORRECTION}

The participants' cautiousness and conservativeness that was reflected in their judgments about their competitors in Vonk's study (1998) and in our study may possibly be due to a motivation to avoid risk. Expecting competition may make people more sensitive to risk. Many findings show that people are risk averse (e.g., Kahneman \& Tversky, 1979). People who expect competition may want to reduce or avoid risk. Additionally, people may feel uncertain about their judgments when inferring their opponent's disposition from a situationally constrained behavior. Since situational constraints, such as situational inducements, may make a particular behavior seem probable, regardless of whether the target possesses that particular disposition, such constraints will reduce the diagnostic value of the behavior that reflects the corresponding disposition, resulting in uncertain dispositional inferences (Trope, 1998). Therefore, people probably are not certain whether their dispositional inferences about situationally constrained behaviors of their opponent are accurate. Competition is also known to enhance the desire to be accurate (Ruscher \& Fiske, 1990) as well as the desire to derogate one's opponent (Klein \& Kunda, 1992). However, it is difficult to know whether one's judgments are accurate, and a derogatory judgment may result in underestimating one's opponent. So judgments which can reduce or avoid risk may suit interpersonal competitors better.

Alternatively, the results of the present research seem to indicate that a competitor's inferential tendency is probably caused by interactions between the desire to avoid risk and the desire to be accurate. People possess many possible goals when processing information (e.g., Chen \& Chaiken, 1999). Ruscher, Fiske, and Schnake (2000) found that incompatible goals produced more complicated impression formation strategies and resulted in more complex impressions. Although the present research showed that the inferential pattern about an opponent's situationally constrained behavior is complex, direct investigation is needed to discover the mechanism for the motivation underlying this process.

As for the desire to derogate one's opponent, it is probably more likely to appear and to bias dispositional inferences when the power of the interpersonal competitors is asymmetrical. Studies have found the powerful are more vulnerable to stereotyping others (e.g., Fiske, 1993; Goodwin, Gubin, Fiske, \& Yzerbyt, 2000), pay more attention to positive and rewarding information (e.g., Anderson \& Berdahl, 2002; Smith \& Bargh, 2008), and prefer to identify others' actions at a more abstract level (Smith \& Trope, 2006, Study 2). Power is also found to increase optimism in perceiving risks and to lead to more risky behavior (Anderson \& Galinsky, 2006). It is probable that high power competitors may derogate their opponents and that their dispositional inferences may not be as cautious and conservative as those of low power competitors. Therefore, future research which investigates whether high power competitors derogate their opponents, pay attention to situational constraints of their opponent's behavior, and make situational corrections about their opponents' behaviors which reflect threatening dispositions may yield interesting results. 


\section{SELF-ASSESSMENTS AND COMPETITORS' SITUATIONAL CORRECTION}

Other factors, such as assessments of or confidence in one's own ability and tactics may also affect the cautiousness and the dispositional inferences of competitors. People in competition are interdependent, and winning a competition depends not only on the opponent's ability and tactics, but also on one's own. The findings of Windschitl, Kruger, and Simms (2003) suggest that competitors' assessments of their own strengths and weaknesses have great impact when they judge their likelihood of winning. Insufficient situational correction due to cautiousness and conservativeness is probably more likely to occur when competitors are not confident in their ability and tactics or when competitors believe that their ability is about the same level as their opponent's. In addition, the importance of the outcome of a competition may affect competitors' cautiousness.

\section{CULTURAL DIFFERENCES AND SITUATIONAL CORRECTION IN COMPETITION}

The participants in this research were Japanese. Although previous crosscultural studies have demonstrated that Asians (e.g., Chinese, Koreans) are less apt to attribute behavior to an actor's personal disposition and more apt to attribute behavior to the situational context than are Westerners (Choi, Nisbett, \& Norenzayan, 1999; Morris \& Peng, 1994), many findings suggest that both Asians (e.g., Japanese, Chinese, and Koreans) and Westerners (e.g., Americans) show an equally strong dispositional bias, that is, they do not make a sufficient situational correction when another's behavior is situationally constrained (Choi \& Nisbett, 1998, Study 1; Krull, Loy, Lin, Wang, Chen, \& Zhao, 1999; Toyama, 1990, 1998, 1999) except in the following situations: When the situational constraint of a behavior is sufficiently salient (Choi \& Nisbett, 1998, Study 2) and when the situationally constrained behavior is minimally diagnostic (Miyamoto \& Kitayama, 2002). Dispositional bias may thus be relatively universal. Nevertheless, whether Western participants expecting interpersonal competition will follow the same inferential tendency as was found in the present research needs further investigation.

\section{INTERGROUP COMPETITION AND SITUATIONAL CORRECTION}

Group bias (Tajfel, 1982) has been found to influence dispositional inferences about out-group members, and situational correction is more likely to occur when people make inferences from out-group members' situationally constrained positive behaviors (Vonk \& Konst, 1998). Ruscher, Fiske, Miki, and Van Manen (1991) also found that people who expect intergroup competition are more likely to make stereotypical judgments about members of the competitive group. Studies by Corneille, Yzerbyt, Rogier, and Buidin (2001) found that participants inferred relatively more extreme and more homogeneous attitudes about the members of a threatening group even when information 
existed which could have been used to discount the extremity and homogeneity of the attitude inference. These studies suggest that insufficient situational correction and dispositional bias are more likely to occur when the behavior of a competitive group reflects a threatening disposition. That is, when facing competition with a group, if a situational correction or a discount could decrease the threat level of the dispositions and catch people off guard, one group may not make a sufficient situational correction about the threatening dispositions of the opponent group, even though they have noticed that the opponents' behavior was constrained by a situational factor.

\section{SITUATIONAL CORRECTION AND DECISION MAKING IN COMPETITION}

When they expect to interact with others, people predict others' behaviors and make decisions about their own behaviors on the basis of their dispositional inferences (Heider, 1944, 1958). However, insufficient situational correction may cause improper predictions and decisions. For example, in a mixed motive interaction, such as PD, one important motive for choosing to compete is fear-fear of being defeated by one's opponent, if one chooses to cooperate (Yamagishi, 1986, 1992). Insufficient situational correction about an opponent's behavior which reflects a threatening disposition may lead to overestimating the threat from the opponent, strengthening a person's fear of being defeated, and as a result stimulating more competition than is necessary. Therefore, an interesting area to investigate would be whether insufficient situational correction about an opponent's behavior that reflects a threatening disposition is related to predictions about an opponent's behavior and people's decisions about their subsequent behaviors.

The present studies demonstrated when and why insufficient situational correction and dispositional bias occur in interpersonal competition. The results of the present studies imply that although an insufficient situational correction or discount can protect competitors from the risk of underestimating their opponent, it may be an important factor in causing excessive competition. However, people may not be aware of the fact that what the excessive competition brings them may be that they will be "sorry" rather than "safe."

\section{REFERENCES}

Anderson, C., \& Berdahl, J. L. (2002). The experience of power: Examining the effects of power on approach and inhibition tendencies. Journal of Personality and Social Psychology, 83, 1362-1377.

Anderson, C., \& Galinsky, A. D. (2006). Power, optimism, and risk-taking. European Journal of Social Psychology, $36,511-536$.
Bargh, J. A. (1994). The four horsemen of automaticity: Awareness, intention, efficiency, and control in social cognition. In R. S. Wyer \& T. K. Srull (Eds.), Handbook of social cognition (pp. 1-40). Hillsdale, NJ: Erlbaum.

Berscheid, E., Graziano, W., Monson, T., \& Dermer, M. (1976). Outcome dependency: Attention, attribution, and at- 
traction. Journal of Personality and Social Psychology, 34, 978-989.

Bierbrauer, G. (1979). Why did he do it? Attribution of obedience and the phenomenon of dispositional bias. European Journal of Social Psychology, 9, 67-84.

Bond, M. H. (1979). Winning either way: The effect of anticipating a competitive interaction on person perception. Personality and Social Psychology Bulletin, 5, 316-319.

Chan, E., \& Ybarra, O. (2002). Interaction goals and social information processing: Underestimating one's partners but overestimating one's opponents. Social Cognition, 20, 409-439.

Chen S., \& Chaiken, S. (1999). The heuristic systematic model in its broader context. In S. Chaiken \& Y. Trope (Eds.), Dual-process theories in social psychology (pp. 73-96). New York: Guilford.

Choi, I., \& Nisbett, R. E. (1998). Situational salience and cultural differences in the correspondence bias and actorobserver bias. Personality and Social Psychology Bulletin, 24, 949-960.

Choi, I., Nisbett, R. E., \& Norenzayan, A. (1999). Causal attribution across cultures: Variation and universality. Psychological Bulletin, 125, 47-63.

Corneille, O., Yzerbyt, V. Y., Rogier, A., \& Buidin, G. (2001). Threat and group attribution error: When threat elicits judgments of extremity and homogeneity. Personality and Social Psychology Bulletin, 27, 437-446.

Czopp, A. M., Monteith, M. J., \& Mark, A. Y. (2006). Standing up for a change: Reducing bias through interpersonal confrontation. Journal of Personality and Social Psychology, 90, 784-803.

Deutsch, M. (1960). The effect of motivational orientation upon trust and suspicion. Human Relations, 13, 123-139.

Deutsch, M. (1962). Cooperation and trust; Some theoretical notes. In M. Jones (Ed.), Nebraska symposium on motivation (pp. 275-319). Lincoln, NE: University of Nebraska Press.

Deutsch, M. (1973). The resolution of conflict: Constructive and destructive processes. New Haven, CT: Yale University Press.
Erber, R., \& Fiske, S. T. (1984). Outcome dependency and attention to inconsistent information. Journal of Personality and Social Psychology, 47, 709-726.

Fiske, S. T. (1993). Controlling other people: The impact of power on stereotyping. American Psychologist, 48, 621-628.

Gawronski, B. (2003). Implicational schemata and the correspondence bias: On the diagnostic value of situationally constrained behavior. Journal of Personality and Social Psychology, 84, 1154-1171.

Gilbert, D. T., \& Jones, E. E. (1986). Perceiver-induced constraint: Interpretations of self-generated reality. Journal of Personality and Social Psychology, 50, 269-280.

Gilbert, D. T., \& Malone, P. S. (1995). The correspondence bias. Psychological Bulletin, 117, 21-38.

Gilbert, D. T., Pelham, B. W., \& Krull, D. S. (1988). On cognitive busyness: When person perceivers meet person perceived. Journal of Personality and Social Psychology, 54, 733-740.

Goodwin, S. A., Gubin, A., Fiske, S. T., \& Yzerbyt, V. Y. (2000). Power can bias impression processes: Stereotyping subordinates by default and by design. Group Processes $\mathcal{E}$ Intergroup Relations, 3, 227-256.

Heider, F. (1944). Social perception and phenomenal causality. Psychological Review, 51, 358-374.

Heider, F. (1958). The psychology of interpersonal relations. New York: Wiley.

Johnson, D. W., \& Johnson, R. (1989). Cooperation and competition: Theory and research. Edina, MN: Interaction Book Company.

Jones, E. E. (1979). The rocky road from acts to dispositions. American Psychologist, $34,107-117$.

Jones, E. E. (1990). Interpersonal perception. New York: W. H. Freeman.

Jones, E. E., \& Harris, V. A. (1967). The attribution of attitudes. Journal of Abnormal and Social Psychology, 3, 1-24.

Kahneman, D., \& Tversky, A. (1979). Prospect theory: An analysis of decision under risk. Econometrica, 47, 263-91. 
Kelley, H., \& Thibaut, J. (1978). Interpersonal relations: $A$ theory of interdependence. New York: Wiley.

Klein, W. M., \& Kunda, Z. (1992). Motivate person perception: Construction justifications for desired beliefs. Journal of Experimental and Social Psychology, 28, 145-168.

Krull, D. S., Loy, M. H., Lin, J., Wang, C., Chen, S., \& Zhao, X. (1999). The fundamental fundamental attribution error: Correspondence bias in individualist and collectivist cultures. Personality and Social Psychology Bulletin, 25, 1208-1219.

Li, Y. M. (2004). Utilization of situational factor in correspondence inference: Effect of motivation. Unpublished doctoral dissertation, Hitostubashi University, Tokyo, Japan.

Miller, D., Norman, S., \& Wright, E. (1978). Distortion in person perception as a consequence of the need for effective control. Journal of Personality and Social Psychology, 36, 598-607.

Miyamoto, Y., \& Kitayama, S. (2002). Cultural variation in correspondence bias: The critical role of attitude diagnosticity of socially constrained behavior. Journal of Personality and Social Psychology, 83, 1239-1248.

Morris, M. W., Larrick, R. P., \& Su, S. K. (1999). Misperceiving negotiation counterparts: When situationally determined bargaining behaviors are attributed to personality traits. Journal of Personality and Social Psychology, 77, 52-67.

Morris, M. W., \& Peng, K. (1994). Culture and cause: American and Chinese attributions for social and physical events. Journal of Personality and Social Psychology, 67, 949-971.

Murata, K. (1982). Attribution processes in a mixed-motive interaction: The role of active observer's behavior. Behaviormetrika, 12, 47-61.

Neuberg, S. L., \& Fiske, S. T. (1987). Motivational influences on impression formation: Outcome dependency, accuracy-driven attention, and individuating processes. Journal of Personality and Social Psychology, 53, 431-444.
Ross, L. (1977). The intuitive psychologist and his shortcomings. In L. Berkowitz (Ed.), Advances in experimental social psychology (Vol. 10). New York: Academic.

Ross, L., \& Ward, A. (1995). Psychological barriers to dispute resolution. In $\mathrm{M}$. Zanna (Ed.), Advances in experimental social psychology (Vol. 27, pp. 255-304). San Diego, CA: Academic.

Ruscher, J. B., \& Fiske, S. T. (1990). Interpersonal competition can cause individuating processes. Journal of Personality and Social Psychology, 58, 832-843.

Ruscher, J. B., Fiske, S. T., Miki, H., \& Van Manen, S. (1991). Individuating processes in competition: Interpersonal versus intergroup. Personality and Social Psychology Bulletin, 17, 595-605

Ruscher, J. B., Fiske, S. T. \& Schnake, S. B. (2000). The motivated tactician's juggling act: Compatible versus incompatible impression goals. British Journal of Social Psychology, 39, 241-256.

Sabatier, P., Hunter, S., \& McLaughlin, S. (1987). The devil shift: Perceptions and misperceptions of opponents. $P o-$ litical Research Quarterly, 40, 449-476.

Skowronski, J. J., \& Carlston, D. E. (1989). Negativity and extremity biases in impression formation: A review of explanations. Psychological Bulletin, 105, 131-142.

Smith, P. K., \& Bargh, J. A. (2008). Nonconscious effects of power on basic approach and avoidance tendencies. Social Cognition, 26, 1-24.

Smith, P. K., \& Trope, Y. (2006). You focus on the forest when you're in charge of the trees: Power priming and abstract information processing. Journal of Personality \& Social Psychology, 90, 578-596.

Stevens, L., \& Fiske, S. T. (2000). Motivated impressions of powerholder: Accuracy under task dependency and misperception under evaluation dependency. Personality and Social Psychology Bulletin, 26, 907-922.

Tajfel, H. (1982). Social identity and intergroup relations. Cambridge, England: Cambridge University Press.

Taylor, S. E. (1991). Asymmetrical effects of positive and negative events: The mo- 
bilization-minimization hypothesis. Psychological Bulletin, 110, 67-85.

Toyama, M. (1990). The role of causal inference in attitude attribution. Paper presented at the 22nd International Congress of Applied Psychology, Kyoto, Japan.

Toyama, M. (1998). Correspondence bias in attitude attribution. Paper presented at the 62nd Conference of the Japanese Psychological Association, Tokyo.

Toyama, M. (1999). Correspondence bias in attitude attribution (2). Paper presented at the 63rd Conference of the Japanese Psychological Association, Nagoya, Japan.

Trope, Y. (1998). Dispositional bias in person perception: A hypothesis-testing perspective. In J. M. Darley \& J. Cooper (Eds.), Attribution and social interaction: The legacy of Edward E. Jones (pp. 67-97). Washington, DC: American Psychological Association.

Vonk, R. (1998). Effects of cooperative and competitive outcome dependency on attention and impression preferences. Journal of Experimental Social Psycholo$g y, 34,265-288$.

Vonk, R. (1999). Effects of outcome dependency on correspondence bias. Perso- nality and Social Psychology Bulletin, 25, 382-389.

Vonk, R., \& Konst, D. (1998). Intergroup bias and correspondence bias: People engage in situational correction when it suits them. British Journal of Social Psychology, 37, 379-385.

Windschitl, P. D., Kruger, J., \& Simms, E. N. (2003). The Influence of egocentrism and focalism on people's optimism in competitions: When what affects us equally affects me more. Journal of Personality and Social Psychology, 85, 389-408.

Yamagishi, T. (1986). The provision of a sanctioning system as a public good. Journal of Personality and Social Psycho$\log y, 51,110-116$.

Yamagishi, T. (1992). Group size and the provision of a sanctioning system in a social dilemma. In W. B. G. Liebrand, D. M. Messick, \& H. Wilke (Eds.), Social dilemmas: Theoretical issues and research findings. International series in experimental social psychology (pp. 267-287). New York: Pergamon. 
Copyright of Social Cognition is the property of Guilford Publications Inc. and its content may not be copied or emailed to multiple sites or posted to a listserv without the copyright holder's express written permission. However, users may print, download, or email articles for individual use. 